\title{
Autologous fibrin-coated small-caliber vascular prostheses improve antithrombogenicity by reducing immunologic response
}

\author{
Tomomi Hasegawa, MD, PhD, Kenji Okada, MD, PhD, Yoshihito Takano, Yoshiaki Hiraishi, and Yutaka Okita, MD, PhD
}

Supplemental material is available online.
From the Division of Cardiovascular, Thoracic, and Pediatric Surgery, Department of Cardio-Pulmonary and Vascular Medicine, Kobe University Graduate School of Medicine, Kobe, and R \& D Center, Terumo Corporation, Kanagawa, Japan.

Yoshihito Takano and Yoshiaki Hiraishi are employed by Terumo, the manufacturer of the graft described in this study. Yutaka Okita reports grant support from Mitsubishi Pharma Research Foundation. Kenji Okada reports grant support from the Japan Society for the Promotion of Science.

Received for publication June 3, 2006; revisions received Dec 14, 2006; accepted for publication Dec 18, 2006.

Address for reprints: Kenji Okada, MD, $\mathrm{PhD}$, Division of Cardiovascular, Thoracic, and Pediatric Surgery, Department of Cardio-Pulmonary and Vascular Medicine, Kobe University Graduate School of Medicine, 7-5-2 Kusunoki-cho, Chuo-ku, Kobe, 650-0017, Japan.

J Thorac Cardiovasc Surg 2007;133:1268-76 $0022-5223 / \$ 32.00$

Copyright (๑) 2007 by The American Association for Thoracic Surgery

doi:10.1016/j.jtcvs.2006.12.049
Objective: We have recently developed a thrombin-free fibrin-coated vascular prosthesis that has a high performance rate in producing graft antithrombogenicity. We hypothesized that autologous, compared with xenologous, fibrin coatings could improve the antithrombogenicity of grafts by reducing immunologic response.

Methods: Autologous fibrin-coated vascular prostheses and/or xenologous fibrincoated vascular prostheses (internal diameter, $2 \mathrm{~mm}$; length, $2.5 \mathrm{~cm}$ ) were implanted in the bilateral carotid arteries of 50 Japanese white rabbits. They were classified into 2 groups by the selection of grafts in the individual: group I (autologous fibrin-coated vascular prosthesis and xenologous fibrin-coated vascular prosthesis); and group II (group IIa: both autologous fibrin-coated vascular prostheses, or group IIx: both xenologous fibrin-coated vascular prostheses). During a maximum of 180 days after implantation, we evaluated the thrombotic, inflammatory, and immunologic responses associated with both types of graft.

Results: All grafts were patent at each end point. In group I, both platelet deposition and anti-graft antibodies in autologous fibrin-coated vascular prostheses were significantly less than those in xenologous fibrin-coated vascular prostheses until postoperative day 30. At postoperative day 10, there were significantly fewer CD45-positive infiltrating cells in autologous fibrin-coated vascular prostheses, and intercellular adhesion molecule-1, vascular cell adhesion molecule-1, and nuclear factor-kappa B expression in autologous fibrin-coated vascular prostheses were less than those in xenologous fibrin-coated vascular prostheses. The neointimal hyperplasia in autologous fibrin-coated vascular prostheses was significantly decreased at postoperative day 180. In group II, serial changes of serum levels of immunoglobulin $\mathrm{M}$, immunoglobulin $\mathrm{G}$, interleukin-1 $\beta$, and tissue-type plasminogen activator/ plasminogen activator inhibitor- 1 ratio in autologous fibrin-coated vascular prostheses were significantly less than those in xenologous fibrin-coated vascular prostheses. In both grafts, platelet deposition significantly correlated with serum immunoglobulin $\mathrm{G}$ level and tissue-type plasminogen activator/plasminogen activator inhibitor-1 ratio.

Conclusion: These findings suggest that autologous fibrin coating in thrombin-free fibrin-coated vascular prostheses improve antithrombogenicity by reducing immunologic response and have a potential for clinical use in hybrid small-caliber vascular grafts.

I $\mathrm{n}$ the development of small-caliber vascular prostheses, antithrombogenicity plays a decisive role in the graft patency. ${ }^{1}$ Recently, the search for an ideal prosthetic vascular graft has evolved from the development of inert, passive materials to the creation of active biomaterials that induce beneficial graft-tissue interaction. The principles of tissue engineering have elicited some encouraging results in various laboratories. ${ }^{2,3}$ However, these techniques require weeks of 


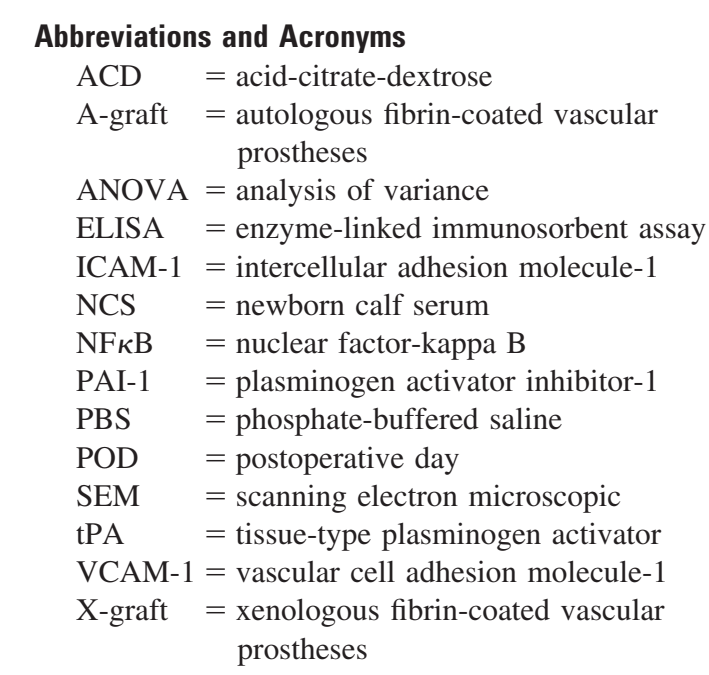

culture before use, because of the large number of cells needed for seeding, and cause a problem because of the delamination of seeded cells by hemodynamic shear stress ${ }^{4}$ and disruption of them by activated leukocytes ${ }^{5}$ in the acute phase of implantation.

Our concept of the hybridization of vascular prostheses was based on a combination of biomaterial and selfregenerative principles. A recent study reported that fibrin matrix might have many advantages, such as promoting cell migration and matrix synthesis and reducing toxic degradation and inflammatory reaction. ${ }^{6}$ Because of its biocompatibility, fibrin matrix is also thought to interact with tissues and blood without inducing thrombus formation. ${ }^{7}$ Currently, we have developed a thrombin-free fibrin-coated small-caliber vascular prosthesis. ${ }^{8}$ Although conventional fibrin coatings in vascular grafts were composed of fibrinogen and thrombin, our fibrin coating was produced by the conversion of fibrinogen without additional thrombin. We documented that the 2-mm thrombin-free fibrin-coated vascular prostheses with xenologous fibrin had a good performance of antithrombogenicity with a patency rate of $100 \%$ after 2 months.

However, it is generally accepted that the recipient reaction due to immunologic response is one reason for graft bioincompatibility after the implantation of vascular prostheses. ${ }^{9,10}$ Activation of the immune system has been indicated as a further factor involved in the graft patency of vascular prostheses. On the other hand, autologous blood donation is generally effective in preventing adverse effects of allogeneic blood donation, including immunologic response. ${ }^{11}$ Therefore, we hypothesized that autologous, compared with xenologous, fibrin coating in small-caliber vascular grafts could suppress the immunologic response and improve graft antithrombogenicity. The purpose of the present study was to evaluate antithrombogenic and immunologic responses associated with autologous fibrin coating in our small-caliber vascular prostheses.

\section{Materials and Methods}

Fifty Japanese white rabbits weighing 2.5 to $3.5 \mathrm{~kg}$ were used. The handling of laboratory animals and their use in experiments conformed to the Guidelines for Animal Experiment at Kobe University Graduate School of Medicine and the Guide for the Care and Use of Laboratory Animals published by the National Academy Press. $^{12}$

\section{Preparation of Vascular Prostheses}

Knitted polyester fabric vascular prostheses with an elastic spinal outer reinforcer (internal diameter, $2 \mathrm{~mm}$; water porosity, 4000 $\mathrm{mL} / \mathrm{min} / \mathrm{cm}^{2}$ at $120 \mathrm{~mm} \mathrm{Hg}$; Terumo Co., Kanagawa, Japan) were used as a basic matrix and were coated with autologous fibrin (A-graft) or xenologous fibrin (X-graft) by a thrombin-free fibrin coating technique. ${ }^{8}$ Briefly, $40 \mathrm{~mL}$ of blood with $8 \mathrm{~mL}$ of acidcitrate-dextrose (ACD) anticoagulant solution was collected from the rabbit itself for A-graft or from a human donor for X-graft. After centrifugation at $1000 \mathrm{~g}$ for 20 minutes at $20^{\circ} \mathrm{C}$, the plasma was slowly incubated with an equal volume of hydroxyethylpiperazineethane sulfonic acid buffered saline solution (HEPES buffer, $\mathrm{pH}$ 7.4) containing $16 \%$ ethanol and shaken for 1 hour at $0^{\circ} \mathrm{C}$ to $4^{\circ} \mathrm{C}$. After centrifugation at $1000 \mathrm{~g}$ for 20 minutes at $4{ }^{\circ} \mathrm{C}$, the supernatant was removed and the precipitate was dissolved in HEPES buffer ( $\mathrm{pH}$ 7.4) with a fibrinogen concentration of 20 $\mathrm{mg} / \mathrm{mL}$. The fibrinogen solution was gently mixed with a solution containing $9 \mathrm{mmol} / \mathrm{L} \mathrm{CaCl}_{2}, 103 \mathrm{mmol} / \mathrm{L} \mathrm{NaCl}, 4 \mathrm{mmol} / \mathrm{L}$ $\mathrm{KCl}$, and $28 \mathrm{mmol} / \mathrm{L}$ sodium lactate for a polymerization of fibrin. Before the fibrin polymerization, the fibrin solution was immediately applied to the knitted polyester fabric vascular prosthesis by injection under pressure. The graft was coated with the polymerized fibrin within 10 minutes. The graft was air-dried for 30 minutes at $25^{\circ} \mathrm{C}$. There was no difference in the graft preparation between A-grafts and X-grafts. The thrombin-free fibrin-coated vascular grafts were sterilely preserved at $4^{\circ} \mathrm{C}$ until graft implantation.

\section{Graft Implantation}

Animals were anesthetized with an initial intravenous dose of 20 $\mathrm{mg} / \mathrm{kg}$ of pentobarbital sodium. Additional local anesthesia, containing $1 \%$ lidocaine, was applied in the cervical portion. Using a sterile technique, A-grafts and/or X-grafts (length, $2.5 \mathrm{~cm}$ ) were implanted in bilateral common carotid arteries as described previously. ${ }^{8}$ Neither antiplatelet nor anticoagulant therapy was administered after graft implantation.

We evaluated both A-grafts and X-grafts in different groups, which were divided by the selection of implanted grafts in the individual rabbit as follows. In group I, animals $(n=40)$ had a different graft-A-graft and X-graft—on each side. In the identical animal, both grafts were compared for graft patency, histology, and thrombotic, inflammatory, and immunologic responses at 1, 3, $7,10,14,30,60$, and 180 days after implantation (5 animals in each end point). In group II, animals had the same graft-A-graft and A-graft (group IIa, $\mathrm{n}=5$ ) or X-graft and X-graft (group IIx, $\mathrm{n}=5$ ) - on both sides. In both subgroups, systemic thrombotic, 
inflammatory, and immunologic responses were evaluated before graft implantation and 1, 3, 7, 10, 14, 30, 60, and 180 days after implantation by using serial blood samples.

\section{Graft Explantation}

In group I, grafts were explanted at each end point under the same general anesthesia as that of graft implantation. Before explantation, blood samples were collected and the graft patency was examined in the graft and distal artery. After heparin sodium (200 $\mathrm{IU} / \mathrm{kg}$ ) was administrated intravenously to prevent clotting, grafts were explanted and gently flushed with normal saline solution to remove any external blood. Animals were killed with a lethal dose of intravenous potassium chloride. After explantation, the graft was evaluated on platelet deposition and then cut into two longitudinal halves. One specimen was evaluated for graft histology, immunohistochemistry, and scanning electron microscopic (SEM) examination, and the other specimen was used to detect anti-graft antibodies by enzyme immunoassay.

\section{Microscopic Evaluation}

Specimens were fixed in $10 \%$ formaldehyde, embedded in paraffin, and cut along the longitudinal axis. Hematoxylin-eosin (HE) and immunohistochemical stains were obtained. The neointimal hyperplasia was quantified near the proximal anastomosis and at the center of the graft with the NIH image program (version 1.63, National Institutes of Health, Bethesda, MD). The thickness of the neointima was determined from the mean thickness at 5 longitudinal sections. Immunohistochemical stainings were performed with a Vectastain Elite ABC kit (Vector Laboratories, Burlingame, CA). Nuclei were counterstained with hematoxylin. As primary antibodies to evaluate inflammatory response in both grafts, mouse anti-human intercellular adhesion molecule-1 (ICAM-1, Zymed Laboratories, South San Francisco, CA), vascular cell adhesion molecule-1 (VCAM-1, Lab Vision, Fremont, CA), nuclear factorkappa B (NFкB, Lab Vision), and CD45 (Zymed Laboratories) were used. The number of CD45-positive cells was quantified by counting immunoreactive cells in 10 nonoverlapping high-power fields. The luminal surfaces of the graft specimens were observed with SEM. Each specimen was fixed with $1 \%$ glutaraldehyde and processed by postfixation in $1 \%$ osmium tetroxide, freeze-dried, and sputter-coated with platinum.

\section{Radiolabeling of Platelets and Quantification of Graft Platelet Deposition}

Twenty-four hours before graft harvest, autologous platelets were labeled with radioactive ${ }^{111}$ Indium (In) and reinjected intravenously, as previously described. ${ }^{8,13}$ Briefly, autologous platelets were incubated with 10 to $37 \mathrm{MBq}$ of ${ }^{111}$ In-oxyquinoline solution (Amersham International, Buckinghamshire, UK) for 10 minutes at $37^{\circ} \mathrm{C}$. After centrifugation $(1000 \mathrm{~g}$ for 10 minutes), the pellet was resuspended in $5 \mathrm{~mL}$ of normal saline/ACD solution and reinjected into the ear vein of a rabbit. The mean labeling efficiency was $86.4 \% \pm 5.2 \%$. After the grafts were explanted, ${ }^{111}$ In-labeled platelet deposition of the graft was measured immediately by a gamma well counter (1470 WIZARD; Wallac, Turku, Finland). Graft radioactivity was expressed as counts per minute. Total platelet deposition of the graft was normalized to graft surface area and number of ${ }^{111} \mathrm{In}$-labeled platelets.

\section{Detection of Anti-graft Antibodies by Enzyme Immunoassay}

Anti-graft antibodies, defined as immunoglobulin (Ig) G antibodies against the implanted vascular prostheses, were detected by a previously described enzyme-linked immunosorbent assay (ELISA) with modifications. ${ }^{14}$ Briefly, a segment (length, $5 \mathrm{~mm}$ ) of each graft specimen was placed into polystyrene tube (low binding capacity) with phosphate-buffered saline (PBS; $\mathrm{pH}$ 7.4) containing $20 \%$ newborn calf serum (NCS) for 16 hours at $4{ }^{\circ} \mathrm{C}$ to block nonspecific binding ( $1 \mathrm{~mL} /$ tube). After 4 washes with PBS containing $0.05 \%$ Tween 20 (PBST), each plasma sample diluted $1 / 100$ in PBST/NCS was added into the tube (500 $\mu \mathrm{L} /$ tube) and incubated with shaking for 1 hour at room temperature. After 6 washes, bound IgG on the graft segment was detected by incubation with shaking for 1 hour at room temperature with horseradish peroxidase-conjugated goat anti-rabbit IgG (Fc-specific; Chemicon International, Temecula, CA, USA) diluted $1 / 5000$ in PBST/NCS (500 $\mu \mathrm{L} /$ tube). After another 6 washes, chromogenic substrate solution containing $3.7 \mathrm{mmol} o$-phenylenediamine dihydrochloride (Wako Pure Chemical Industries, Osaka, Japan) and $0.012 \% \mathrm{H}_{2} \mathrm{O}_{2}$ in hydrogenphosphate $(85 \mathrm{mmol} / \mathrm{L}) /$ citric acid $(35 \mathrm{mmol} / \mathrm{L})$ buffer ( $\mathrm{pH} 5.5)$ were added (100 $\mu \mathrm{L} /$ tube). After 0.5 hours of incubation in the dark, the reaction was stopped by $4 \mathrm{~mol} / \mathrm{L} \mathrm{H}_{2} \mathrm{SO}_{4}(500$ $\mu \mathrm{L} /$ tube), and each sample was transferred into 96-well microtiter plates. Optical density was measured at $490 \mathrm{~nm}\left(\mathrm{OD}_{490}\right)$ on the Model 550 microplate reader (Bio-Rad Laboratories, Hercules, CA, USA).

\section{Biochemical Analyses by Enzyme Immunoassay}

In group II, serum levels of IgM, IgG, interleukin-1 $\beta$ (IL-1 $\beta$ ), tissue-type plasminogen activator (tPA), and plasminogen activator inhibitor-1 (PAI-1) were serially measured by ELISA. All blood samples were collected via an ear vein and centrifuged immediately. The plasma was frozen and stored until biochemical analyses were performed. Commercial kits for IgG, IgM (Bethyl Laboratories, Montgomery, TX), IL-1 $\beta$ (BioSource, International, Camarillo, CA), tPA, and PAI-1 (Biopool International, Ventura, CA $)^{15}$ were used for the analyses. The tPA/PAI-1 ratio was calculated to provide insights about the relative fibrinolytic "balance" in each subgroup.

\section{Statistical Analysis}

Database management and statistical analysis were performed with the Statview (Version 5.0) software package (Abacus Concepts Inc, Berkeley, CA). All values are expressed as the means \pm standard deviation (SD). In group I, comparisons between both grafts were performed with Student $t$ test. In group II, serial changes of serum biochemical levels in both subgroups were compared by a repeated-measures analysis of variance (ANOVA). Simple linear regression analysis was performed by the least squares method to determine the relationship between serum biochemical level and platelet deposition in both grafts.

\section{Results \\ Graft Patency and Appearance}

Both A-grafts and X-grafts were patent without macroscopic thrombus or stenosis at each end point of graft 

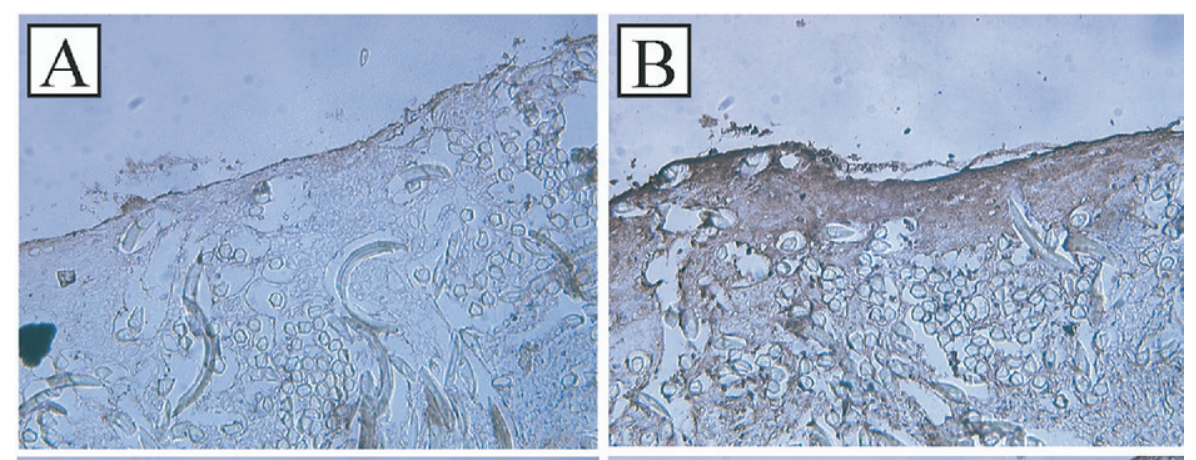

Figure 1. Immunohistochemistry. (Left) Autologous fibrin-coated vascular prostheses (A-graft). (Right) Xenologous fibrin-coated vascular prostheses (Xgraft). A, B, ICAM-1; C, D, VCAM-1; E, $\mathrm{F}, \mathrm{NF} \kappa \mathrm{B}$ (original magnifications $\times 20$ ); G, H, CD45 (original magnifications $\times 40$ ). Note the decrease in I-CAM-1, VCAM-1, NF $\kappa$ B, and CD45 expression in A-grafts.
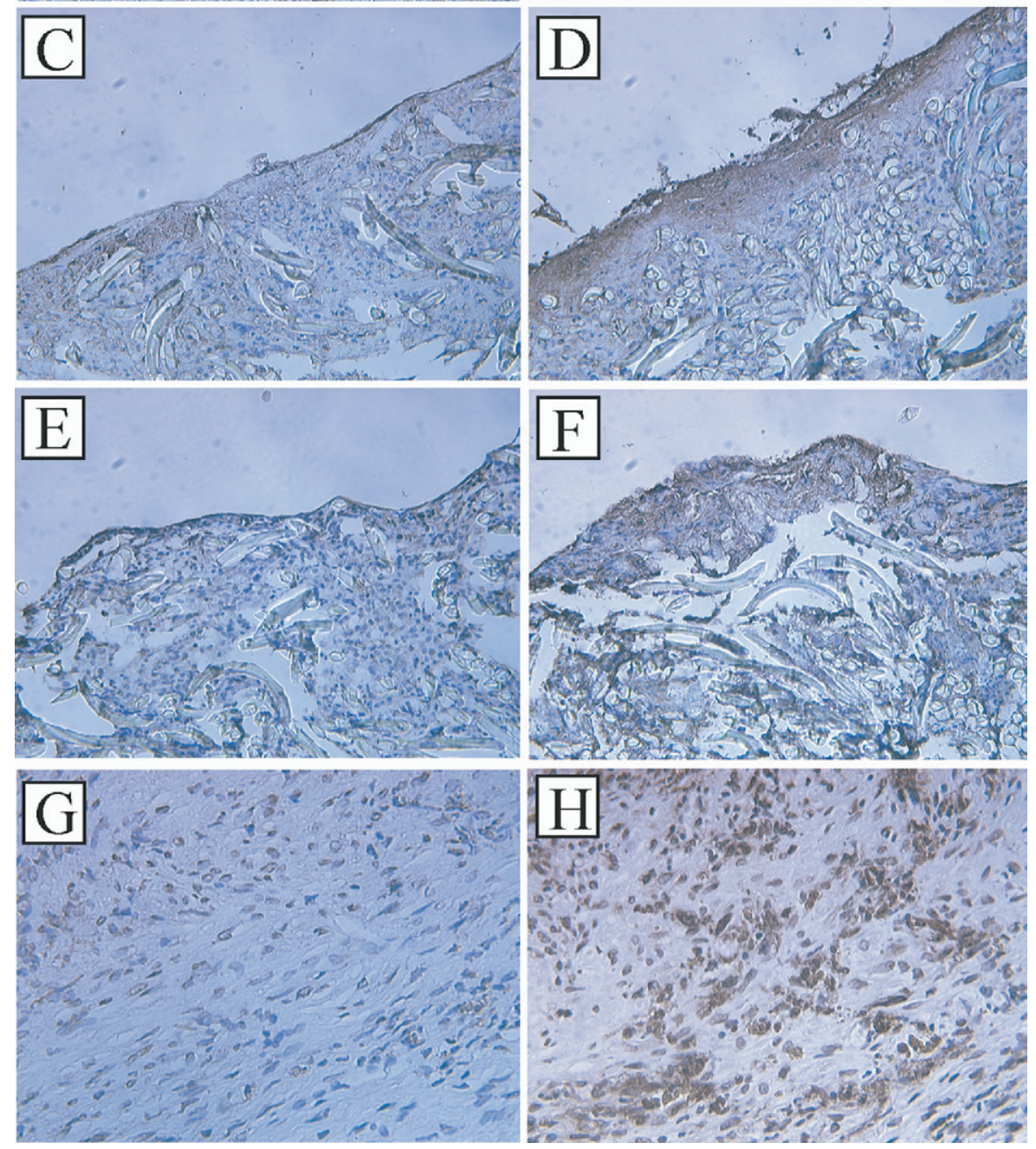

explantation throughout the 180 days of follow-up. The histologic findings indicate that the fibrin coating in both grafts started to be absorbed gradually after graft implantation and was completely degraded and replaced with neofibrin net between postoperative day (POD) 7 and POD 14 . During this period, the inflammatory response with full-wall cellular infiltration in A-grafts was observed to be less severe than that in $\mathrm{X}$-grafts. Immunohistochemical studies indicated that the expressions of ICAM-1, VCAM-1, and
$\mathrm{NF} \kappa \mathrm{B}$ in A-grafts were less than those in X-grafts. There were also significantly fewer CD45-positive cells in Agrafts than those in X-grafts ( $74 \pm 16$ vs $233 \pm 35$ cells per high power field, $P<.0001$, Figure 1). SEM studies on POD 10 revealed that the adhesion of activated platelets on the luminal surface in A-grafts was less than that in X-grafts at each point of graft explantation (Figure E1). After POD 14 , neointimal formation on the luminal surface and smallcapillary formation arising from the surrounding connective 


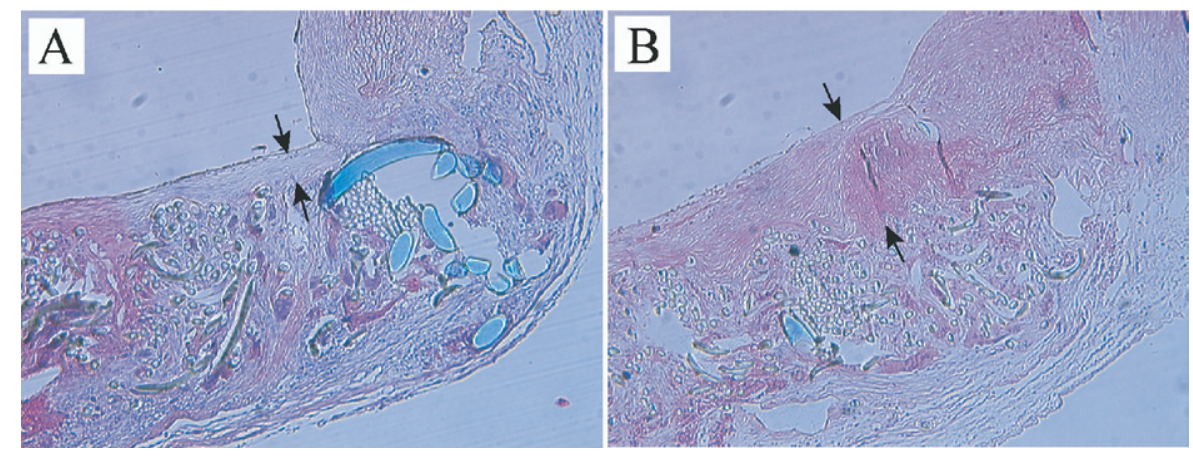

Figure 2. Neointimal hyperplasia at anastomosis site. HE stain (original magnification $\times 20$ ). A, Autologous fibrincoated vascular prostheses. B, Xenologous fibrin-coated vascular prostheses. Note the significant decrease in neointimal thickness (arrows) in A-grafts.

tissues were observed in both grafts. At POD 180, the neointima in A-grafts was significantly thinner than those in X-grafts $(50.9 \pm 12.8$ vs $237.6 \pm 23.4 \mu \mathrm{m}$ at the anastomosis site, $26.3 \pm 9.2$ vs $168.4 \pm 21.7 \mu \mathrm{m}$ at the central site, $P<.0001$, respectively, Figure 2 ).

\section{Quantification of Platelet Deposition}

${ }^{111}$ In-labeled platelet scintigraphy results in group I are shown in Figure 3. In both grafts, a very low amount of platelets was deposited on the graft until POD 3. However, after that, the platelet deposition increased steeply and reached a maximal level on POD 10. The maximal platelet depositions in A-grafts were $10.3 \pm 1.6 \times 10^{6} / \mathrm{mm}^{2}$, whereas those in X-grafts were $17.4 \pm 1.4 \times 10^{6} / \mathrm{mm}^{2}$. A large amount of platelets were deposited on the graft until POD 14, and then the platelet deposition decreased gradually. Platelet deposition in A-grafts was significantly less than that in X-grafts until POD 30 (POD 1, 3, 7, 10, and 14, respectively, $P<.01$; POD $30, P=.029)$.

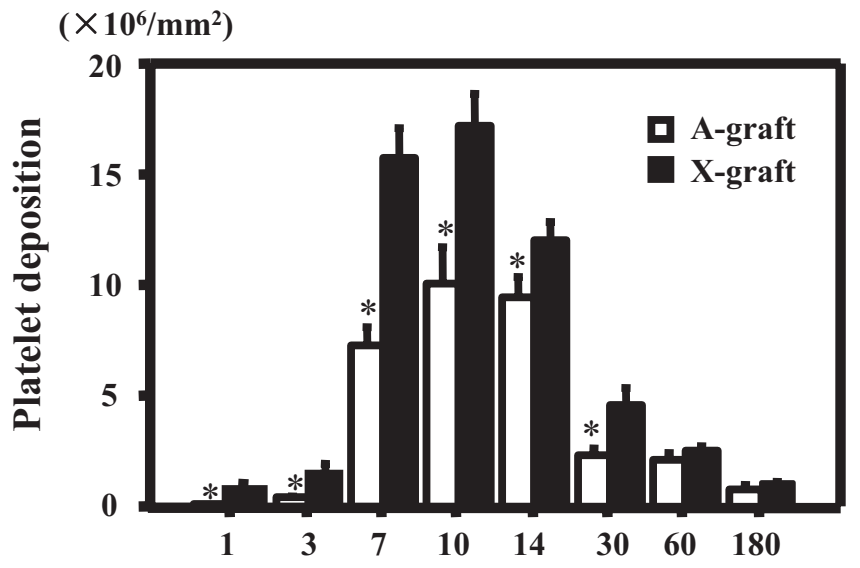

Days after graft implantation

Figure 3. Platelet deposition. Platelet deposition in autologous fibrin-coated vascular prostheses was significantly less than that in xenologous fibrin-coated vascular prostheses until postoperative day 30 . Values are given as mean \pm SD. ${ }^{*} P<.05$.

\section{Anti-graft Antibody Formation}

Anti-graft antibodies against A-grafts and X-grafts after implantation were sensitively detected in group I. In both grafts, anti-graft antibody elevated to the peak on POD 1 quickly and then decreased gradually. The maximal level of anti-graft antibody in A-grafts was $0.17 \pm 0.02 \mathrm{OD}_{490}$, whereas that in X-grafts was $0.46 \pm 0.06 \mathrm{OD}_{490}$. Anti-graft antibodies in A-grafts remained at low levels at every point of the study protocol and were significantly less than those in X-grafts until POD 30 (POD 1, 3, 7, and 10, respectively, $P<.001$; POD 14 and 30, respectively, $P<.01$ ).

\section{Serial Changes of Serum IgM, IgG, IL-1 $\beta$,} tPA, and PAI-1

In both subgroups, serum IgM levels increased sharply to a peak on POD 3 and then decreased quickly, whereas serum IgG levels increased to a peak on POD 10 and decreased gradually. However, serum IgM and IgG levels in group IIa were quite low at every point and were significantly less than those in group IIx throughout the 180 days of follow-up (by ANOVA, $P<.0001$, respectively, Figure 4). On POD 10, serum IL- $1 \beta$ in group IIa reached the maximal level of $400.3 \pm 27.0 \mathrm{pg} / \mathrm{mL}$, whereas it was $882.8 \pm 102.2 \mathrm{pg} / \mathrm{mL}$ in group IIx. Serum IL-1 $\beta$ levels in group IIa were low at every point and significantly less than those in group IIx throughout the 180 days of follow-up (by ANOVA, $P<$ .0001). There was no statistically significant difference in the serial change of serum PAI-1 between both subgroups, whereas serum tPA level in group IIa was significantly less than that in group IIx (by ANOVA, $P<.0001$ ). The mean baseline of tPA/PAI-1 ratio before graft implantation was $0.26 \pm 0.08$. Compared with the baseline, the tPA/PAI-1 ratios in both subgroups increased after graft implantation and reached a peak on POD 10. The tPA/PAI-1 ratio in group IIa was significantly less than that in group IIx (by ANOVA, $P<.0001$, Figure 5).

\section{Correlations of Serum IgG Level and tPA/PAI-1 Ratio} With Platelet Deposition

Simple linear regression analyses of serum IgG level, tPA/ PAI-1 ratio, and platelet deposition are illustrated in Figure 6. 


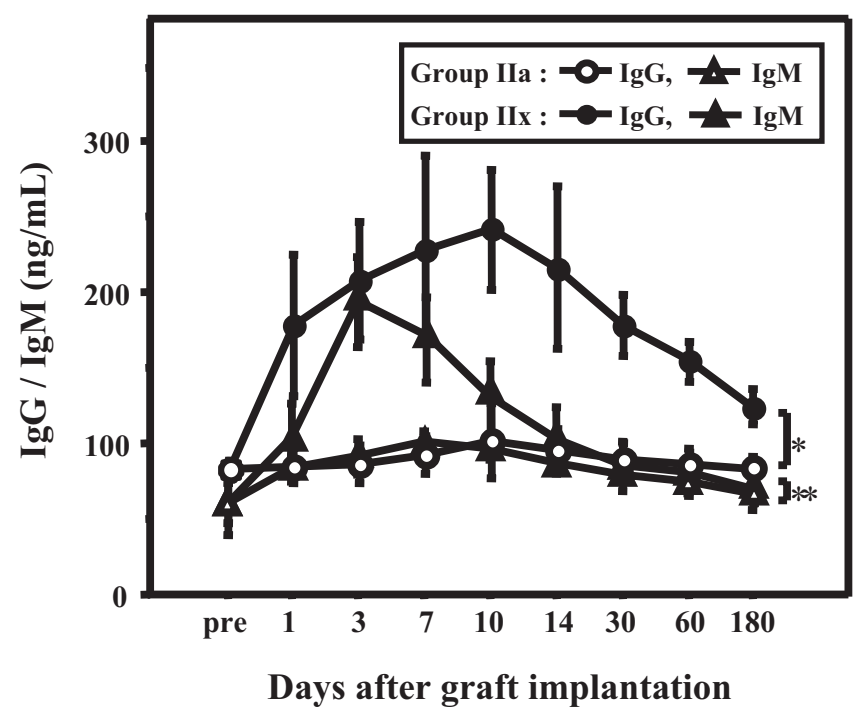

Figure 4. Serum levels of $\lg M$ and $\lg G$. Serial changes of serum $\lg M$ and $\lg G$ levels in autologous fibrin-coated vascular prostheses (group Ila) were significantly less than those in xenologous fibrin-coated vascular prostheses (group IIx). Values are given as mean \pm SD. ${ }^{*} \boldsymbol{P}<.05$ (ANOVA) in IgG; ${ }^{*} \boldsymbol{P}<.05$ (ANOVA) in IgM.

Serum IgG level correlated significantly with platelet deposition in both A-grafts $(P<.0001, r=.698)$ and $\mathrm{X}$-grafts $(P<.0001, r=.725)$, and tPA/PAI-1 ratio correlated significantly with platelet deposition in both A-grafts $(P<$ $.0001, r=.850)$ and $\mathrm{X}$-grafts $(P<.0001, r=.839)$.

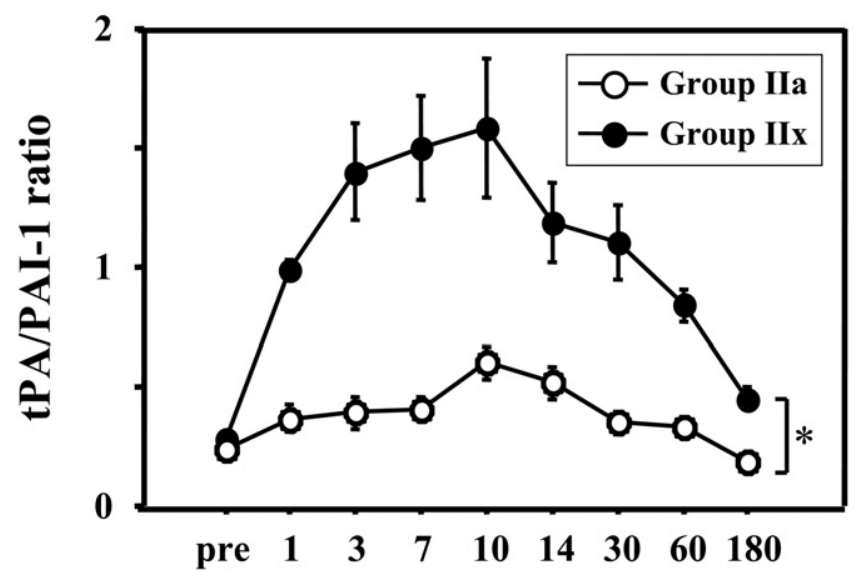

\section{Days after graft implantation}

Figure 5. Serum levels of $\mathrm{PA} / \mathrm{PAI}-1$ ratio. The tPA/PAI-1 ratio in autologous fibrin-coated vascular prostheses (group Ila) was significantly less than those in xenologous fibrin-coated vascular prostheses (group IIx). Values are given as mean \pm SD. ${ }^{*} P<.05$ (ANOVA).

\section{Discussion}

Our 2-mm vascular prostheses with fibrin coating showed high antithrombogenicity in the present study. The patency of both autologous fibrin-coated vascular prostheses (Agrafts) and xenologous fibrin-coated vascular prostheses (X-grafts) was $100 \%$ at each end point of graft explantation throughout the 6 months of follow-up. There were several reports of 2-mm small-caliber vascular prostheses in the rabbit model previously, ${ }^{16-19}$ but their longest patency was $100 \%$ at 2 months after implantation in expanded polytetrafluoroethylene grafts. ${ }^{17}$ Although our results should be assessed with some considerations concerning animal species-dependent thrombogenicity, the graft pal-
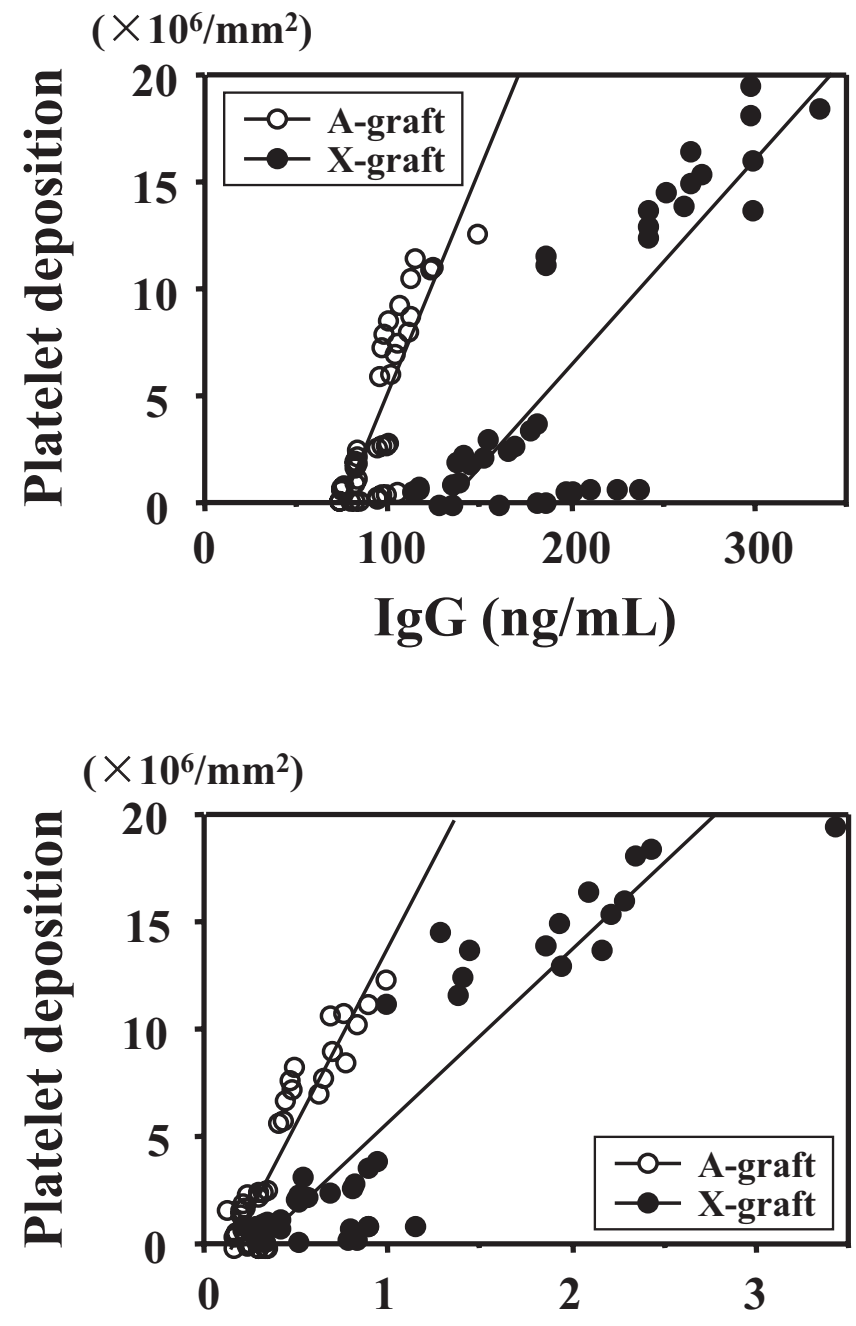

tPA/PAI-1 ratio

Figure 6. Correlations of serum IgG level and tPA/PAI-1 ratio with platelet deposition. Serum IgG level and tPA/PAI-1 ratio correlated significantly with platelet deposition in both grafts $(P<$ .0001, respectively). 
tency of our 2-mm vascular prostheses with fibrin coating was satisfactory. Thrombin-free fibrin-coated vascular prostheses, about which we have previously reported,${ }^{8}$ have a greatly improved antithrombogenicity.

A literature review revealed two reports of a coating of vascular prostheses with autologous fibrin. Kjaergard and Weis-Fogh ${ }^{20}$ described the coating technique of autologous fibrin in high-porosity double-velour vascular prostheses (5 $\mathrm{mm}$ in circumference, $4 \mathrm{~cm}$ in length). Cardon and associates $^{21}$ studied knitted polyester vascular prostheses with autologous fibrin coating $(6 \mathrm{~mm}$ in diameter, 10 to 12 $\mathrm{cm}$ in length) by porcine aortoiliac bypass model. The graft patency in that study was $80 \%$ at 14 days and $55.5 \%$ at 90 days. Their techniques of fibrin coating in vascular prostheses were conventional in that fibrin was produced by fibrinogen and thrombin. Neither report evaluated the immunologic response of their autologous fibrin-coated vascular prostheses.

After the implantation of vascular prostheses, cellular immunologic response, which is mediated by $\mathrm{T}$ lymphocytes and macrophages, plays a central role in the acute inflammatory process. ${ }^{9,10,22}$ In the present study, a smaller number of these CD45-positive cells infiltrated into A-grafts than into X-grafts. ICAM-1, VCAM-1, and NF $\kappa$ B expression in A-grafts decreased after graft implantation, compared with those of X-grafts. Moreover, serum IL- $1 \beta$ levels in A-grafts were significantly less than those in $\mathrm{X}$-grafts throughout 180 days after graft implantation. These results suggest that the autologous fibrin coating suppresses the inflammatory reaction in vascular prostheses. On the other hand, it is still controversial whether the antibody formation induced by humoral immune response is important for the inflammatory process. Recently, Schlosser and colleagues ${ }^{14,23}$ demonstrated the immunogenicity of implanted polyester vascular prostheses with the formation of specific humoral antibodies. They insisted that humoral immune response against implanted components may provide a potential marker that facilitates monitoring of the individual perigraft reaction and the graft biocompatibility. In the present study, the measurement of anti-graft antibodies was useful to evaluate the immunogenicity of A-grafts and Xgrafts themselves. Anti-graft antibodies in A-grafts remained at quite low levels at every point of the study protocol throughout the 180 days of follow-up and was significantly less than the levels in X-grafts until POD 30.

It is well known that normal individuals have natural antibodies that react with a wide variety of antigens in the absence of any evidence of prior exposure. These antibodies are low levels of circulating IgM and IgG antibodies and react systemically not only with infections agents but also with antigens expressed on unrelated tissues. ${ }^{24,25}$ There were many studies for natural antibodies in the field of xenografts, and it was revealed that transplantation of un- related tissues induces a rapid increase of serum $\operatorname{IgM}$ and a subsequent increase of serum IgG. ${ }^{26,27}$ Similar results were observed in serum IgM and IgG levels after implantation of $\mathrm{X}$-grafts in this study. We thought that xenologous fibrin coating of vascular prostheses reacted with natural antibodies as antigens expressed on unrelated tissues. On the other hand, serum $\operatorname{IgM}$ and $\operatorname{IgG}$ in A-grafts remained at low levels after graft implantation. Interestingly, there was close correlation between platelet deposition and serum $\mathrm{IgG}$ level in both grafts. Recently, Colvin and $\mathrm{Smith}^{28}$ reported that antibodies induce graft rejection acutely through the fixation of a complement, resulting in tissue injury and coagulation. Our findings support the view that that immunologic response after graft implantation has an effect on graft thrombogenicity.

Our thrombin-free fibrin-coated vascular prostheses had a tendency to increase platelet deposition between PODs 7 and 14. Because fibrin coating was degraded during this period, we thought that the increase of platelet deposition was caused by the shearing effect of blood according to the degradation of fibrin coating. ${ }^{8}$ However, platelet deposition in A-grafts during the period was approximately $60 \%$ of that in X-grafts in the present study and remained at low levels during the 6 months of follow-up, with a significant decrease until POD 30 . This result strongly suggests that autologous fibrin-coated vascular prostheses have high antithrombogenicity. Previously, we have investigated another fibrin-coated vascular prosthesis with thrombin (internal diameter, $3 \mathrm{~mm}$ ) in coronary artery bypass grafting in a sheep model. ${ }^{29}$ We proved that a large amount of platelets was deposited on the graft surface between PODs 7 and 14 and that the grafts were occluded by thrombus during this period. We believe that it is very important to improve graft antithrombogenicity, especially between PODs 7 and 14, for a successful development of our fibrin-coated vascular prostheses.

In this study, A-grafts induced a decrease in serum tPA activity without affecting serum PAI-1 activity and improved the fibrinolytic balance of tPA/PAI-1 compared with $\mathrm{X}$-grafts. Interestingly, there was a significantly positive correlation between tPA/PAI-1 ratio and platelet deposition in both grafts. We supposed that the decrease of platelet deposition on graft surface in A-grafts may reduce serum tPA activity, leading to adequate lysis of thrombi, following the improvement of fibrinolytic balance.

Knowing how long the fibrin coating lasts is crucial to estimate the long-term results of our fibrin-coated vascular prostheses. Along with degradation, the fibrin coating was completely replaced with a neofibrin net that migrated from blood circulation in the rabbit itself by POD 14 in both grafts. ${ }^{8}$ The neofibrin net consists of autologous fibrin, which means the autologous fibrin coating would last more than 14 days after implantation. Although we do not have 
any data as to how long the neofibrin net lasts in the grafts, we believe that the autologous fibrin coating followed by the neofibrin net induces the excellent graft antithrombogenicity. Further study of the degradation of fibrin coating is needed. There are also inevitable questions whether the neofibrin is the same in both grafts and whether the immunologic responses against them since POD 14 are the same in both grafts. Although the nature of antigens in vascular prostheses is not yet known, Rubin and Matron ${ }^{30}$ recently proved that human fibrinogen induces cross-reactive immunity to mouse fibrinogen in a mouse model with human fibrinogen injected subcutaneously. It is possible that xenologous fibrin in vascular prostheses might induce crossreactive immune response to the neofibrin net of rabbits in this study. Therefore, humoral immune response, inflammatory response, and fibrinolytic imbalance as well as platelet deposition in X-grafts may be kept longer than those in A-grafts after the replacement of fibrin coating. The longstanding nature of these responses to graft injury may cause neointimal hyperplasia in X-grafts. Further study of the nature of antigens in fibrin-coated vascular prostheses is needed.

In addition to reduced immunologic response and thrombogenicity, it is generally agreed that coating with autologous fibrin has 2 more advantages: promotion of graft healing and elimination of the risk of viral transmission. ${ }^{11,21}$ In this study, 1 layer of endothelial-like cells was evident on POD 60 in A-grafts and on POD 180 in X-grafts. Although the presence of these cells was not demonstrated by a typical endothelial cell staining such as von Willebrand factor (data not shown), Cardon and associates ${ }^{21}$ supposed that autologous fibrin matrixes could serve as supports for other molecules such as growth factors or cell material to accelerate endothelialization. Although there was no difference of graft patency between A-grafts and X-grafts in the present study, those advantages of autologous fibrin may result in less neointimal hyperplasia of A-grafts on POD 180.

Our technique can provide a sufficient quality of fibrin coating in vascular prostheses within approximately 3 hours. Although rabbit blood was collected more than 1 month before graft implantation, according to animal care regulations, in this study, human blood can be collected immediately before graft preparation. In addition, we have checked that the experimental grafts were able to be preserved in a sterile condition for at least 6 months. Therefore, our technique can be used in both elective and emergency surgery in clinical settings.

The limitation of this study is that an immunologic reaction of the blood in group I might have had a negative repercussion on both grafts because all rabbits in group I were implanted with X-graft. However, we were afraid that individual differences could affect the results of local reac- tion in implanted grafts, such as graft patency, graft appearance, platelet deposition, and anti-graft antibody formation. In consideration of the negative repercussions, systemic serum reactions in both grafts were evaluated in group II.

In conclusion, autologous fibrin-coated vascular prostheses had less thrombogenicity and reduced immunologic response compared with those of xenologous fibrin-coated vascular prostheses. Moreover, there was a close correlation between platelet deposition and serum IgG levels in vascular prostheses. These results strongly support our hypothesis that autologous fibrin coating can improve antithrombogenicity by reducing immunologic response. Autologous thrombin-free fibrin-coated vascular prostheses have a potential for clinical use in hybrid small-caliber vascular grafts.

This work was supported in part by a Grant-in-Aid for Scientific Research (C) (No. 15591473) from the Japan Society for the Promotion of Science and a research grant from Mitsubishi Pharma Research Foundation.

\section{References}

1. Verma S, Marsden PA. Nitric oxide-eluting polyurethanes-vascular grafts of the future? N Engl J Med. 2005;353:730-1.

2. Conklin BS, Wu H, Lin PH, Lumsden AB, Chen C. Basic fibroblast growth factor coating and endothelial cell seeding of a decellularized heparin-coated vascular graft. Artif Organs. 2004;28:668-75.

3. Hoerstrup SP, Zund G, Sodian R, Schnell AM, Grunenfelder J, Turina MI. Tissue engineering of small caliber vascular grafts. Eur J Cardiothorac Surg. 2001;20:164-9.

4. Feugier P, Black RA, Hunt JA, How TV. Attachment, morphology and adherence of human endothelial cells to vascular prosthesis materials under the action of shear stress. Biomaterials. 2005;26:1457-66.

5. Emerick S, Herring M, Arnold M, Baughman S, Reilly K, Glover J. Leukocyte depletion enhances cultured endothelial retention on vascular prostheses. J Vasc Surg. 1987;5:342-7.

6. Ye Q, Zund G, Benedikt P, Jockenhoevel S, Hoerstrup SP, Sakyama S, et al. Fibrin gel as a three dimensional matrix in cardiovascular tissue engineering. Eur J Cardiothorac Surg. 2000;17:587-91.

7. Bense CA, Woodhouse KA. Plasmin degradation of fibrin coatings on synthetic polymer substrates. J Biomed Mater Res. 1999;46:305-14.

8. Hasegawa T, Okada K, Takano Y, Hiraishi Y, Okita Y. Thrombin-free fibrin coating on small caliber vascular prostheses has high antithrombogenicity in rabbit model. Artif Organs. 2005;29:880-6.

9. Kottke-Marchant K, Anderson JM, Miller KM, Marchant RE, Lazarus H. Vascular graft-associated complement activation and leukocyte adhesion in an artificial circulation. J Biomed Mater Res. 1987;21:379-97.

10. Marois Y, Roy R, Marois M, Guidoin RG, von Maltzahn WW, Kowligi R, et al. T lymphocyte modification with the UTA microporous polyurethane vascular prosthesis: in vivo studies in rats. Clin Invest Med. 1992;15:141-9.

11. Komatsu F, Yoshida S. Large volume apheresis of autologous plasma and preparation of autologous fibrin glue from the plasma. Ther Apher. 2001;5:12-6.

12. Institute of Laboratory Animal Research Commission on Life Sciences NRC. Guide for the care and use of laboratory animals. Washington, DC: National Academy Press; 1996.

13. Thakur ML, Welch MJ, Joist JH, Coleman RE. Indium-111 labeled platelets: studies on preparation and evaluation of in vitro and in vivo functions. Thromb Res. 1976;9:345-57.

14. Schlosser M, Wilhelm L, Urban G, Ziegler B, Ziegler M, Zippel R. Immunogenicity of polymeric implants: long-term antibody response against polyester (Dacron) following the implantation of vascular prostheses into LEW.1A rats. J Biomed Mater Res. 2002;61:450-7. 
15. de las HN, Cediel E, Oubina MP, Aragoncillo P, Sanz-Rosa D, Lahera $\mathrm{V}$, et al. Comparison between the effects of mixed dyslipidaemia and hypercholesterolaemia on endothelial function, atherosclerotic lesions and fibrinolysis in rabbits. Clin Sci (Lond). 2003;104:357-65.

16. Sparks SR, Tripathy U, Broudy A, Bergan JJ, Kumins NH, Owens EL. Small-caliber mesothelial cell-layered polytetraflouroethylene vascular grafts in New Zealand white rabbits. Ann Vasc Surg. 2002;16:73-6.

17. Contreras MA, Quist WC, Logerfo FW. Effect of porosity on smalldiameter vascular graft healing. Microsurgery. 2000;20:15-21.

18. Harada M, Takenaka H, Ikenaga S, Zhang H, Zempo N, Esato K, et al. Hepatocyte growth factor prevents intimal hyperplasia in rabbit carotid expanded polytetrafluoroethylene grafting. J Vasc Surg. 2002;35:786-91.

19. Yoneyama T, Ito M, Sugihara K, Ishihara K, Nakabayashi N. Small diameter vascular prosthesis with a nonthrombogenic phospholipid polymer surface: preliminary study of a new concept for functioning in the absence of pseudo- or neointima formation. Artif Organs. 2000;24:23-8.

20. Kjaergard HK, Weis-Fogh US. Autologous fibrin glue for sealing vascular prostheses of high porosity. Cardiovasc Surg. 1994;2:45-7.

21. Cardon A, Chakfe N, Thaveau F, Gagnon E, Hartung O, Aillet S, et al Sealing of polyester prostheses with autologous fibrin glue and bone marrow. Ann Vasc Surg. 2000;14:543-52.

22. Huang B, Marois Y, Roy R, Julien M, Guidoin R. Cellular reaction to the Vascugraft polyesterurethane vascular prosthesis: in vivo studies in rats. Biomaterials. 1992;13:209-16.
23. Schlosser M, Zippel R, Hoene A, Urban G, Ueberrueck T, Marusch F, et al. Antibody response to collagen after functional implantation of different polyester vascular prostheses in pigs. J Biomed Mater Res A. 2005;72A:317-25.

24. Boyden SV. Natural antibodies and the immune response. Adv Immunol. 1966;5:1-28.

25. Cramer DV. Natural antibodies and the host immune responses to xenografts. Xenotransplantation. 2000;7:83-92.

26. Grimm H, Mages P, Lindemann G, Potthoff M, Bohnet U, Korom S, et al. Evidence against a pivotal role of preformed antibodies in delayed rejection of a guinea pig-to-rat heart xenograft. $J$ Thorac Cardiovasc Surg. 2000;119:477-87.

27. Miyatake T, Sato K, Takigami K, Koyamada N, Hancock WW, Bazin $\mathrm{H}$, et al. Complement-fixing elicited antibodies are a major component in the pathogenesis of xenograft rejection. J Immunol. 1998; 160:4114-23.

28. Colvin RB, Smith RN. Antibody-mediated organ-allograft rejection. Nat Rev Immunol. 2005;5:807-17.

29. Hasegawa T, Okada K, Takano Y, Hiraishi Y, Yoshida Y, Okita Y. Hybrid small-caliber vascular prosthesis for coronary artery bypass grafting: a preliminary study of plasmin-treated fibrin-coated vascular prosthesis. ASAIO J. 2005;51:725-9.

30. Rubin B, Matron C. The mouse immune response to human fibrinogen reveals an autoimmune component against mouse fibrinogen. Cell Immunol. 2005;233:41-52.

Access to The Journal of Thoracic and Cardiovascular Surgery Online is reserved for print subscribers!

Full-text access to The Journal of Thoracic and Cardiovascular Surgery Online is available for all print subscribers. To activate your individual online subscription, please visit The Journal of Thoracic and Cardiovascular Surgery Online, point your browser to http://www.mosby.com/jtcvs, follow the prompts to activate your online access, and follow the instructions. To activate your account, you will need your subscriber account number, which you can find on your mailing label (note: the number of digits in your subscriber account number varies from 6 to 10). See the example below in which the subscriber account number has been circled:

\section{Sample mailing label}

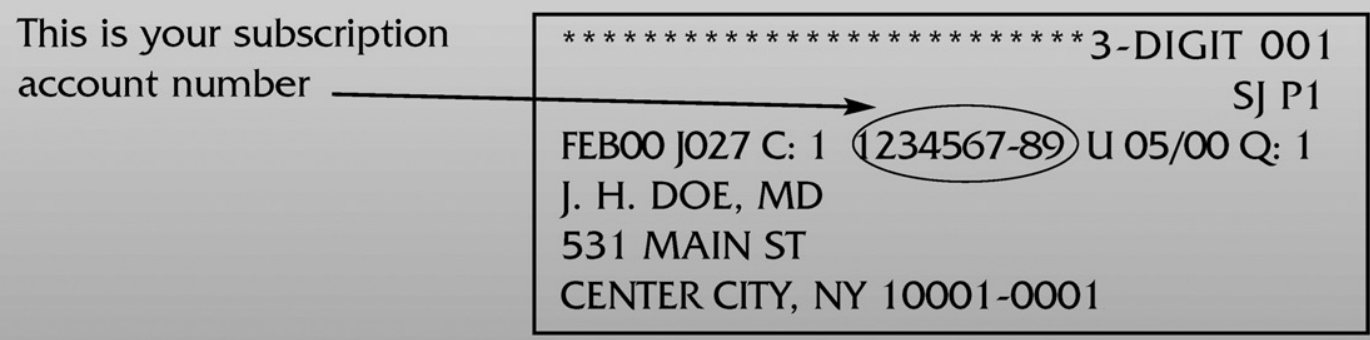

Personal subscriptions to The Journal of Thoracic and Cardiovascular Surgery Online are for individual use only and may not be transferred. Use of The Journal of Thoracic and Cardiovascular Surgery Online is subject to agreement to the terms and conditions as indicated online. 

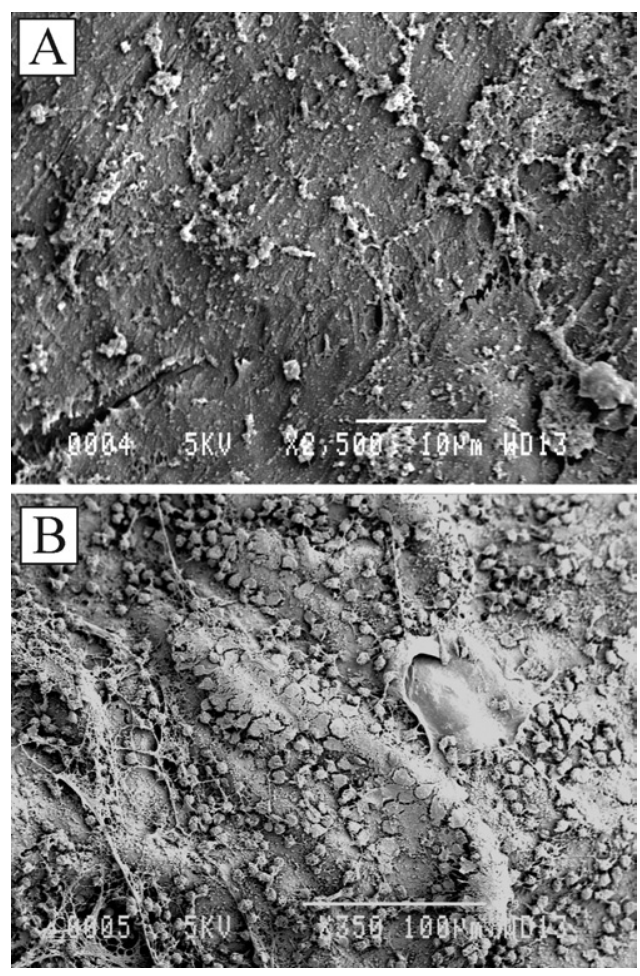

Figure E1. Scanning electron micrographs of the luminal surface on postoperative day 10 (original magnification $\times 2500$ ). A, Autologous fibrin-coated vascular prostheses. B, Xenologous fibrin-coated vascular prostheses. Activated platelets were adhered to and formed aggregates on the luminal surface in both grafts. The platelet adhesion in A-grafts was less than that in X-grafts. 